Canadian Journal of Fisheries and Aquatic Sciences, v. 51, n. 4, 1994, p. 913-922.

All articles in NRC Research Press journals are copyright NRC Research Press or its licensors.

http://pubs.nrc-cnrc.gc.ca/eng/home.html

doi:10.1139/cjfas-51-4-913

\title{
Gape-dependent Larval Foraging and Zooplankton Size: Implications for Fish Recruitment across Systems
}

\author{
Mary T. Bremigan and Roy A. Stein \\ Aquatic Ecology Laboratory, Department of Zoology, The Ohio State University.
}

Small gape of zooplanktivorous larval fish limits their prey size; yet, within constraints set by gape, zooplankton size eaten influences larval growth and ultimately survival. To determine if optimal zooplankton size varied among fish species with different gapes, we conducted foraging trials with larval bluegill (Lepomis macrochirus, 10-26 mm TL) and gizzard shad (Dorosoma cepedianum, 18-31 mm TL). Larvae $(\mathrm{n}=10)$ fed for $1 \mathrm{~h}$ on zooplankton assemblages that varied in size, after which all larvae and remaining zooplankton were preserved. Larval gape was measured; both larval gut contents and available zooplankton were quantified. Bluegill, the large-gaped species, fed on larger zooplankton than did gizzard shad with similar gapes. Further, larger bluegill fed on progressively larger zooplankton whereas all gizzard shad ate small prey $(<0.60 \mathrm{~mm})$. As available zooplankton size increased, bluegill prey size increased whereas gizzard shad consistently selected small prey. Therefore, differences in zooplankton size among lakes could differentially affect foraging success of larval fishes. In particular, systems with small zooplankton may represent ideal foraging environments for gizzard shad whereas lakes with large zooplankton may favor larval bluegill. If differential larval foraging translates to differential growth and survival, zooplankton size could influence recruitment success and ultimately fish community composition.

La petite ouverture de la bouche chez des larves zooplanctivores de poisson les limite dans le choix des proies que ces larves peuvent ingérer; compte tenu de cette contrainte, la taille du zooplancton qui est ingéré influence la croissance des larves et ultimement leur survie. Pour déterminer si la taille optimale du zooplancton ingéré qui varie d'une espèce à l'autre de poisson en fonction de l'ouverture de la bouche, nous avons procédé à des essais d'alimentation sur des larves du crapet arlequin (Lepomis macrochirus, LT 10-26 mm) et de l'alose à gésier (Dorosoma cepedianum, LT $18-31 \mathrm{~mm})$. Les larves $(\mathrm{n}=10)$ ont été nourries pendant $1 \mathrm{~h}$ avec des groupes zooplanctoniques variables quant à leur taille; au bout de cette période, toutes les larves et le zooplancton qui restait ont été conservés. L'ouverture de la bouche des larves a été mesurée; le contenu stomacal des larves ainsi que le zooplancton ont été mesurés. Le crapet arlequin, l'espèce à la plus grande bouche, s'est nourri d'un zooplancton plus gros que celui des aloses qui avaient une bouche de la même grandeur. En outre, les plus grosses larves du crapet arlequin se sont nourries de zooplancton de plus en plus gros alors que toutes les larves de l'alose ont ingéré des petites proies $(<0,60 \mathrm{~mm})$. Plus le zooplancton restant était gros, plus le crapet se nourrissait de proies de plus en plus grosses; l'alose choisissait constamment de petites proies. Donc, des différences d'un lac à l'autre dans la taille du zooplancton pourraient agir différentiellement sur le succès de l'alimentation des larves de poisson. En particulier, les systèmes où on trouve du 
zooplancton de petite taille peuvent correspondre à un environnement idéal d'alimentation pour l'alose à gésier alors que les lacs qui comptent du zooplancton de grande taille peuvent être plus avantageux pour le crapet arlequin. Si les habitudes alimentaires différentielles des larves se traduisent par une croissance et une survie différentielles, alors la taille du zooplancton pourrait agir sur le succès du recrutement et, ultimement, sur la composition des communautés de poisson.

Identifying mechanisms underlying fish recruitment ultimately will improve our understanding of community dynamics and patterns of species distributions. However, despite its significance, recruitment historically has been difficult to predict. Recent studies, illustrating the utility of a size-based perspective, demonstrate that many factors affecting survival of larval fishes are size dependent (Forney 1976; Hunter 1981; Post and Prankevicious 1987; Rice et al. 1987; Luecke et al. 1990). Larger larvae tend to be more resistant to starvation, stronger swimmers, less vulnerable to predation (Miller et al. 1988), better foragers (Blaxter 1986; Pepin 1991), and less vulnerable to overwinter mortality (Adams et al. 1982) than their smaller counterparts. Therefore, understanding the processes that underlie larval growth is a critical component of predicting recruitment. Larval growth, in turn, requires successful foraging (Noble 1975; Mills et al. 1989a). Given these linkages among foraging, growth, and size-dependent survival, we may ultimately be able to predict recruitment by identifying ideal foraging environments for larval fish.

Both food quantity and quality drive larval foraging success. Therefore, not only the absolute abundance, but also the size distribution of zooplankton available to larval fishes influences their foraging success, as well as growth (Arthur 1976; Frank and Leggett 1986; Crowder et al. 1987; Mills et al. 1989a, 1989b; Miller et al. 1990) and survival (Ware 1975, 1977; Frank and Leggett 1986), suggesting that an optimal prey size exists for larval fish. Because previous studies have focused on the relationship between single fish species and zooplankton size, we adopted a multispecies approach to determine if the relationship between zooplankton size and larval foraging is species specific. Further, we evaluated the utility of larval gape in explaining patterns of prey choice.

Larval gape influences larval foraging by constraining the size of zooplankton that larval fish can capture and consume (Wong and Ward 1972; Schael et al. 1991). Therefore, gape should correspond to larval prey size. Because gape varies both within species (through ontogeny) and among species (gape versus length varies with species), it may function as a predictor of prey choice, both within and across fish species. Specifically, differences in gape size between fish species may indicate that they have different optimal zooplankton sizes. Yet, gape alone does not predict prey choice because factors such as visual acuity and foraging mode influence larval foraging as well. Accordingly, within a single system, larvae of different species, with similar gapes, do feed on zooplankton of different sizes (Arthur 1976; Hartmann 1986; Michaletz et al. 1987; Schael et al. 1991). How gape contributes to foraging patterns across fishes requires refinement, for species-specific differences in optimal prey size have important implications for larval success.

Because zooplankton size varies among systems, species-specific differences in optimal prey size could contribute to recruitment patterns (Sprules 1980; Bays and Crisman 1983; Canfield 1988). Whereas some systems are dominated by large zooplankton, such as Daphnia or large copepods, others are dominated by small zooplankton, such as Bosmina or small copepods. 
Given the likelihood of species-specific responses to zooplankton size, systems that differ in zooplankton size may represent ideal foraging, and hence recruitment, environments for different larval fishes.

We documented the foraging patterns of two fish species across a gradient of zooplankton size and evaluated the role of gape in larval prey choice. We chose bluegill (Lepomis macrochirus) and gizzard shad (Dorosoma cepedianum) for these experiments, given that their geographic distributions overlap (Becker 1983), their larvae are zooplanktivorous (Becker 1983), and, as we document below, their relationships between gape and total length differ. Within species, we asked these questions: Do larvae with larger gapes eat larger prey? Does larval prey size change corresponding to available prey size? If so, does an interaction exist between the effects of gape and available prey size on prey choice? Between fish species, we asked: Do larvae with similar gapes eat similar-sized prey? Do larvae respond to zooplankton size similarly? Finally, if species-specific patterns of prey choice were evident, our goals were to (1) evaluate the usefulness of gape as a predictor of prey size and (2) consider the implications of these differences in prey choice to foraging success, growth, and ultimately survival of these two fish species, across systems ranging their geographic distribution, with zooplankton assemblages that differ markedly in size.

\section{Methods}

Experimental Organisms

Young-of-year bluegill and gizzard shad were collected from Hebron Fish Hatchery ponds, Hebron, Ohio, during July and August 1990 and held at $23^{\circ} \mathrm{C}$ in a $14 \mathrm{~h}$ light : $10 \mathrm{~h}$ dark cycle. Larvae were fed a mixture of brine shrimp nauplii, reservoir zooplankton, and laboratorycultured Daphnia magna. Because fish size ranged 10-26 mm total length (TL) for bluegill and 18-31 mm TL for gizzard shad, both larvae and early juveniles were used in experiments. Hereafter, all fish will be referred to as larvae.

Using a dissecting scope with a drawing tube, we measured larval total length. Larval dry weight of gizzard shad was calculated with a species-specific regression, determined by drying larvae at $80^{\circ} \mathrm{C}$ for $24 \mathrm{~h}$. A larval bluegill length - dry weight regression was provided by James Breck (Department of Natural Resources, Ann Arbor, Mich.). Larval gapes were measured using a precision gape micrometer, which provides the smallest internal dimension of the mouth (Arts and Evans 1987). This device consisted of stainless steel rods with conical tips that were mounted on a Plexiglas body holding a micrometer scale and measurement head. Gapes of a size-stratified sample of bluegill $(n=39)$ and gizzard shad $(n=47)$ were measured. From these gape measurements, species-specific regressions of gape as a function of total length were developed. Gapes for all larvae used in experiments were calculated with these regressions.

\section{Experimental Protocol}

Zooplankton used in the experiments were composed of reservoir and hatchery pond zooplankton supplemented by laboratory-cultured D. magna. Dominant taxa were Bosmina spp., Chydorus spp., Ceriodaphnia spp., Daphnia spp., and calanoid and cyclopoid copepods.

Foraging experiments were conducted in 8.0-L $\left(23^{\circ} \mathrm{C}\right)$ containers with opaque sides. To ensure that larval guts were empty at the beginning of an experiment, we starved 10 larvae of a 
single species overnight by isolating them in covered containers without zooplankton. Each morning, zooplankton were size-fractionated by first straining them through a $180-\mu \mathrm{m}$-mesh net. Given their small size, rotifers and copepod nauplii were not included in our experiments. Extremely high densities of these small zooplankton would have been required to provide biomasses comparable with large zooplankton, thus confounding zooplankton size and number across containers. Zooplankton retained by the $180-\mu \mathrm{m}$ mesh were strained through a $500-\mu \mathrm{m}-$ mesh net. Zooplankton assemblages were composed of zooplankton (1) retained by the $180-\mu \mathrm{m}$ mesh but not the $500-\mu \mathrm{m}$ mesh (small zooplankton), (2) retained by the $500-\mu \mathrm{m}$ mesh (large zooplankton), or (3) composed of groups 1 and 2, equally mixed (large and small zooplankton). Due to differences in shape among zooplankton taxa, the outcome of size-fractionation varied with taxa. Therefore, rather than creating three distinct zooplankton treatments, this method produced zooplankton assemblages that varied along a size gradient. Each assemblage contained at least 1000 zooplankton $\left(125-\mathrm{L}^{-1}\right)$; numbers were estimated initially by eye and later quantified.

Experiments began at about 08:00. Lights came on at 07:40; light levels ranged from 215 to $350 \mathrm{~lx}$ across containers. At 08:00, covers were removed from the larval fish containers and zooplankton added, with zooplankton assemblages arbitrarily assigned to containers. Larvae fed for $1 \mathrm{~h}$ and were then removed and preserved in $10 \%$ formalin. Remaining zooplankton were preserved in 5\% sugar-buffered formalin. In all, 29 experimental containers contained bluegill; 33 containers contained gizzard shad. Because larvae die if handled, they were not measured before experiments. Therefore, larval size varied both within and across containers. To compare foraging by fishes of a given gape, we considered larvae to be independent units throughout our analysis.

Sample Analysis

To quantify zooplankton consumed by larvae (hereafter referred to as gut zooplankton or prey) and zooplankton remaining in each container at the end of each experiment (container zooplankton), we identified (cladocerans to genus; copepods as calanoid or cyclopoid), counted, and measured zooplankton using a dissecting scope with a drawing tube. For gut zooplankton, the entire digestive tract of each larva was analyzed. In most cases, all prey were measured. In a very few cases, prey were too digested to measure. We assigned measurements to unmeasured prey proportionate to the recorded measurements for prey of that particular taxon in that particular fish. The proportion of prey items in a given fish that were unmeasured never exceeded $50 \%$ and rarely exceeded $20 \%$. For container zooplankton, we counted zooplankton from two opposite wedges of a dish divided into 16 equal-sized wedges. From these counts, the total number of individuals within each taxon in the entire sample was estimated. If this number was $>25$, counting of complete wedges continued until at least 50 individuals of that taxon were counted. If the total number of individuals of a taxon, as estimated from the first two wedges, was $\leq 25$, counting of that taxon stopped because it contributed so little to the entire sample, and the initial estimate of abundance was retained. At least 20 individuals of each taxon were measured (total body length, excluding spines, helmets, and caudal rami). For both gut ad container zooplankton, zooplankton lengths were converted to biomass using taxon-specific length-dry weight regressions (G.G. Mittelbach, Kellogg Biological Station, Michigan State University, East Lansing, Mich., unpublished data).

For each experimental container, gut zooplankton were added to container zooplankton to generate estimates of the zooplankton in each container at the outset of experiments (hereafter 
referred to as available zooplankton). Both average size and number of available zooplankton varied similarly for bluegill and gizzard shad across containers. Average zooplankton size across containers ranged from 0.30 to $1.90 \mathrm{~mm}$; numbers varied from $1000\left(125-\mathrm{L}^{-1}\right)$ to $2600\left(325-\mathrm{L}^{-1}\right)$. Across zooplankton assemblages, average size of available zooplankton tended to decline as number of available zooplankton increased, allowing zooplankton biomass to remain consistent across containers. Therefore, no containers had a high density (i.e., $>300-\mathrm{L}^{-1}$ ) of large zoo plankton (i.e., average size $>0.80 \mathrm{~mm}$ ). At the outset of our analysis, to account for the potential influence of number of available zooplankton, we first tested the influence of both size and number of available zooplankton on larval prey size. Because our analysis did not indicate that number of available zooplankton contributed substantially to patterns in larval prey size, we eliminated it from further analyses.

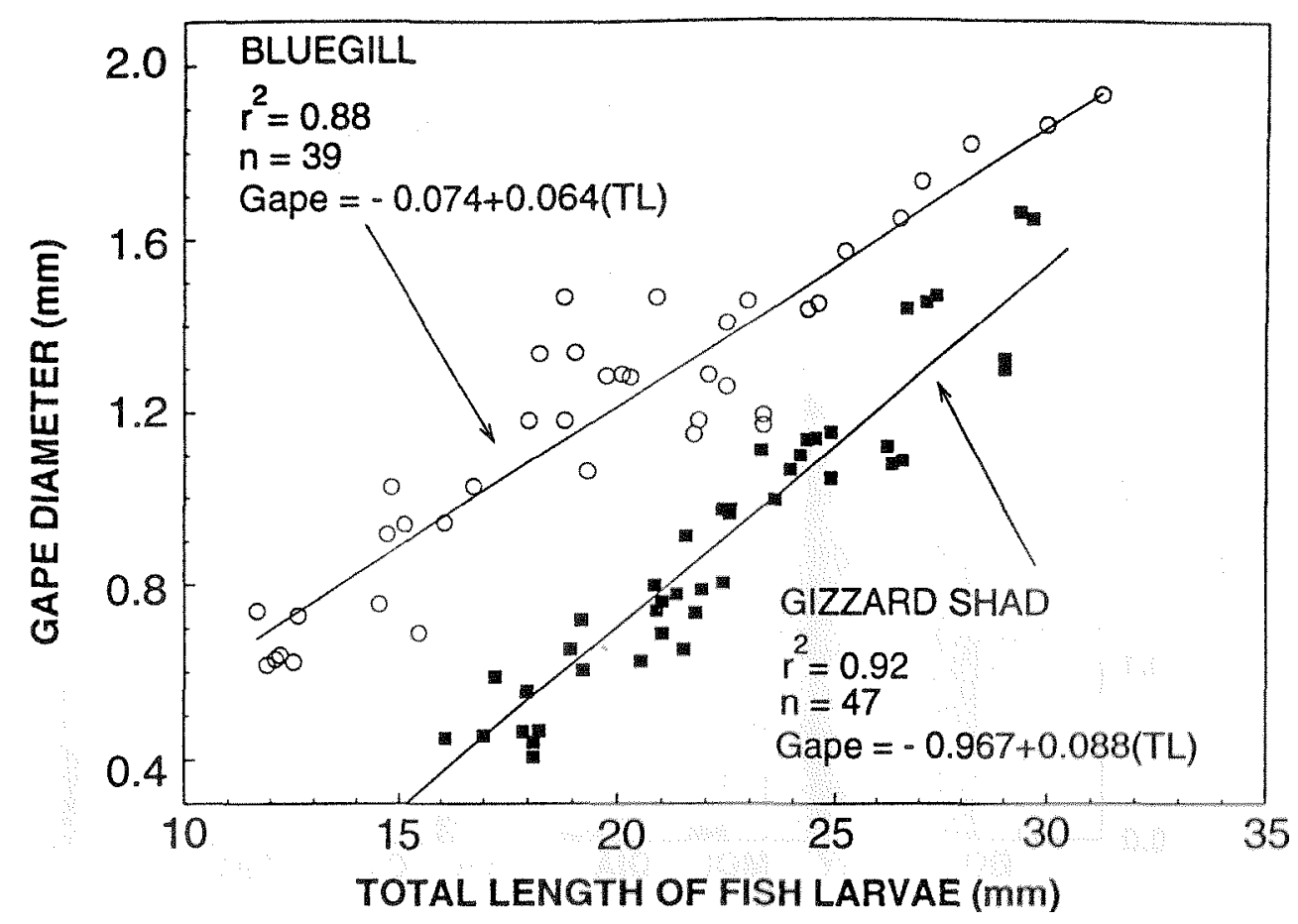

FIG. 1. Gape of larval bluegill and gizzard shad in relation to larval total length.

Results

\section{Larval Gape}

To determine if gape size differences were significant between species, we regressed gape as a function of total length and compared a full model (separate regression lines for bluegill and gizzard shad) with a reduced one (one regression line for all larvae). Bluegill had larger gapes than same-sized gizzard shad (Fig. $1 ; F_{2.82}=190.6, p \leq 0.001$ ). Differences in gape between the two species were greatest for smallest larvae, declining with increasing total length. 


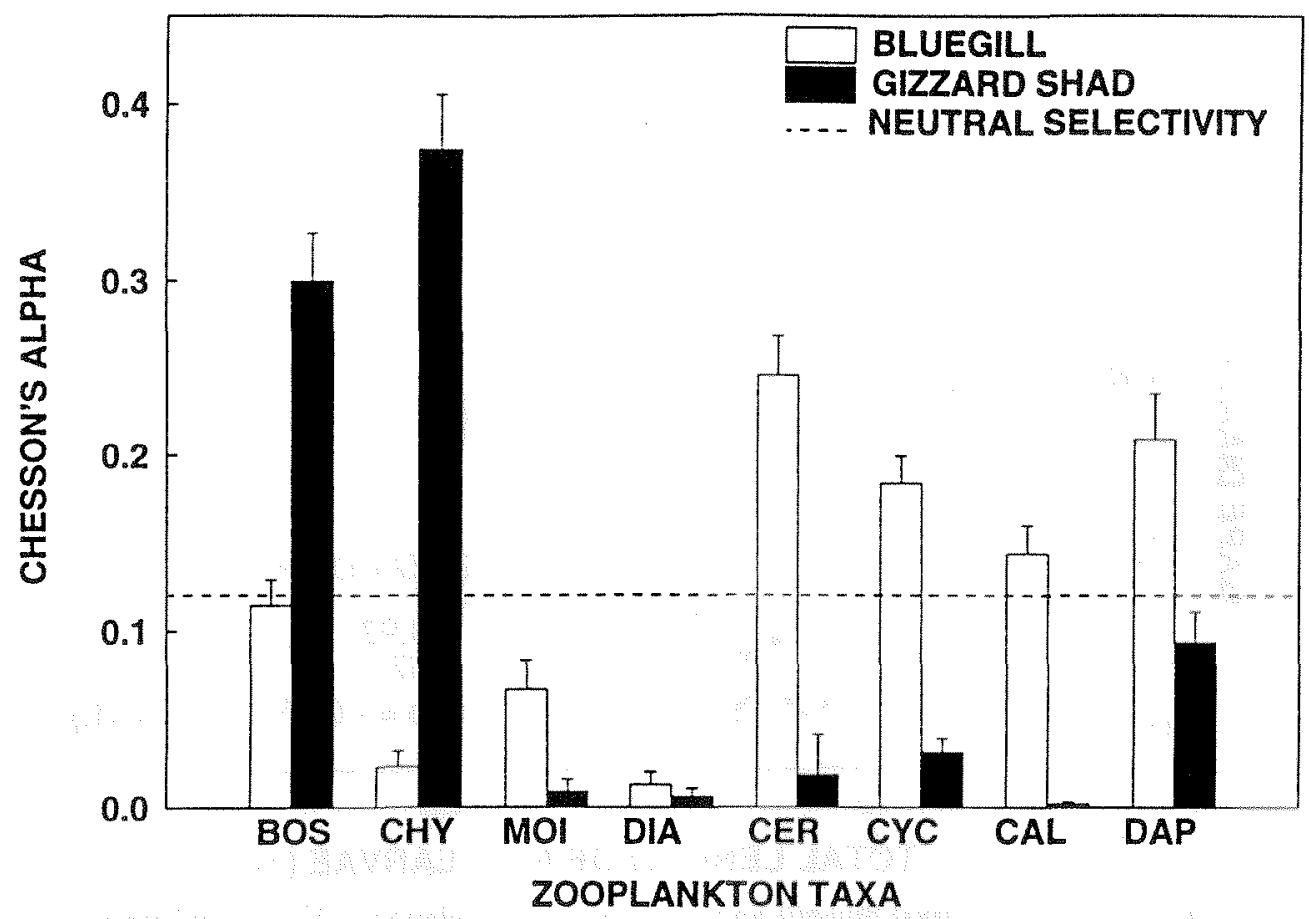

FIG. 2. Taxonomic selection (using Chesson's alpha, Chesson 1978, 1983) by larval bluegill and gizzard shad. Data represent averages across all containers \pm 1 SE. The broken line represents neutral selection (i.e., 0.125, the reciprocal of the number of zooplankton taxa available). Zooplankton taxa: $\mathrm{BOS}=$ Bosmina, $\mathrm{CHY}=$ Chydorus, $\mathrm{MOI}=$ Moina, $\mathrm{DIA}=$ Diaphanosoma, $\mathrm{CER}=$ Ceriodaphnia, $\mathrm{CYC}=$ cyclopoid copepods, $\mathrm{CAL}=\mathrm{calanoid}$ copepods, and DAP = Daphnia. Zooplankton taxa are placed in order of increasing size, from Bosmina, the smallest taxon, to Daphnia, the largest taxon.

Taxonomic Composition of Zooplankton

Because taxonomic composition varied across containers, we first evaluated the taxonomic composition of larval guts to determine if zooplankton taxa could be combined in our analysis of prey size. Neither bluegill nor gizzard shad guts were dominated by a single prey taxon. Bosmina, Ceriodaphnia, and calanoid and cyclopoid copepods were the most common prey of small bluegill. Larger bluegill tended to consume more calanoid copepods and Daphnia, but fewer Ceriodaphnia and Bosmina. For gizzard shad, Bosmina and Chydorus, followed by Ceriodaphnia and Daphnia, were the most common prey. Large gizzard shad tended to consume more Chydorus and fewer Ceriodaphnia. Overall, bluegill and gizzard shad diets varied most in the relative contribution of copepods and Chydorus, with copepods contributing substantially to bluegill gut zooplankton and Chydorus to gizzard shad gut zooplankton. This difference was mirrored in the average percent composition of zooplankton available to bluegill and gizzard shad. However, all of these taxa were available (although to varying degrees) to both bluegill and gizzard shad.

Accordingly, selectivity patterns varied between bluegill and gizzard shad (Fig. 2). Bluegill did not strongly select any particular taxon; in general, bluegill selected Ceriodaphnia and Daphnia and demonstrated slight selection for calanoid and cyclopoid copepods. Gizzard shad strongly selected Chydorus and Bosmina. Calanoid and cyclopoid copepods were avoided 
by gizzard shad.

Overall, bluegill and gizzard shad were exposed to, and consumed, a variety of prey taxa. Because our primary interest was the size of zooplankton eaten in relation to both larval gape and size of zooplankton available to larvae, zooplankton taxa were combined for statistical analyses. Below, when we state that a particular response variable increased or decreased or was related to a set of independent variables, these statements always will be significant at an alpha level of 0.05 .

Prey Size Range across Containers

Across containers, substantial variation in prey size among larvae occurred (Fig. 3). For both bluegill and gizzard shad, minimum prey size remained fairly consistent among larvae across gape. However, maximum prey size appeared larger for bluegill than for gizzard shad. Further, more prey items exceeded gape for bluegill than for shad, probably because calanoid copepods, which are long but slender, were more common to bluegill guts than to gizzard shad guts. Our analyses were directed towards distinguishing the role of gape and available zooplankton size in driving these patterns of prey size of bluegill and gizzard shad.

\section{Within-Species Foraging Patterns}

To evaluate the contribution of gape and average available zooplankton size to larval prey size, we first regressed these two variables, as well as their interaction, against larval prey size (average prey size for each larval fish). Separate regressions were done for bluegill and gizzard shad. For both species, the model explained significant amounts of variability in larval prey size. However, the interaction between gape and size of available zooplankton did not contribute to either model. Therefore, this term was dropped from further analyses, and we evaluated average prey size as a function of available zooplankton size and gape (no interaction term).

Bluegill prey size was explained by this model (Table 1). Specifically, prey size increased as both gape and available zooplankton size increased (Fig. 4). The gizzard shad model also revealed significant differences in prey size among individual larvae (Table 1). Specifically, gizzard shad prey size increased with available zooplankton size, but was unrelated to gape (Fig. 4). However, far less of the variation in prey size was explained by the gizzard shad model $\left(r^{2}=\right.$ $0.12)$ than the bluegill model $\left(r^{2}=0.54\right)$. In particular, the lower $r^{2}$ of the gizzard shad model indicates that variability in gizzard shad prey size was inadequately explained by gape and available zooplankton size. Further, a qualitative comparison of the equation coefficients reveals that prey size increased much more rapidly with available zooplankton size for bluegill than for gizzard shad.

These analyses reveal two important features of larval foraging. First, prey size for both bluegill and gizzard shad varied across experiments, indicating that larval prey choice varied across containers with different zooplankton assemblages or among larvae with different gapes. Second, differences in prey size were related to gape of bluegill, but not to gape of gizzard shad, suggesting that the relationship between gape and prey size varies across fish species. 


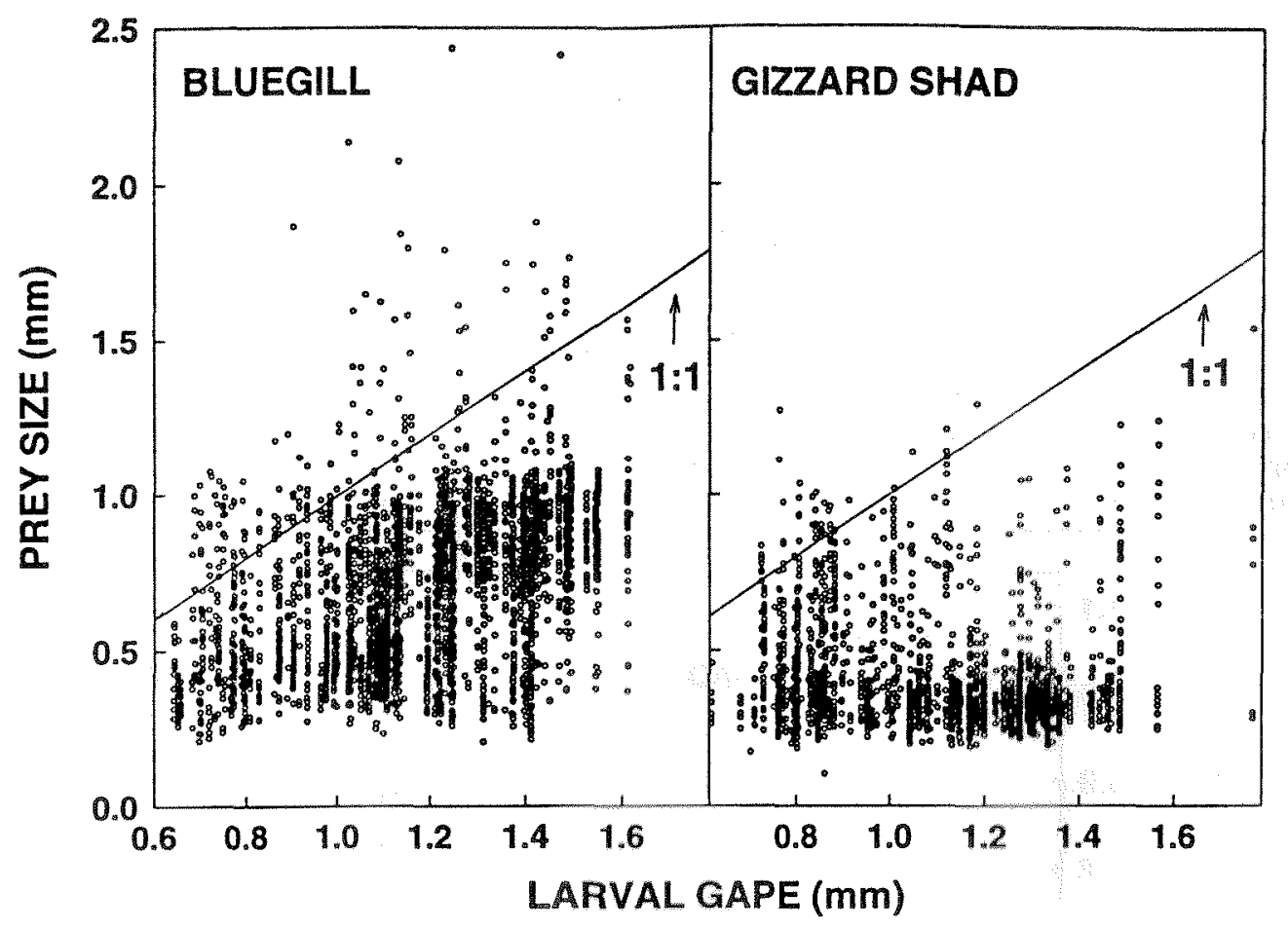

FIG. 3. Relationship between prey size and gape size for larval bluegill $(n=135)$ and gizzard shad $(n=155)$. Each point represents a single prey item. The solid line represents the $1: 1$ line where prey size $=$ gape size.

\section{BLUEGILL}

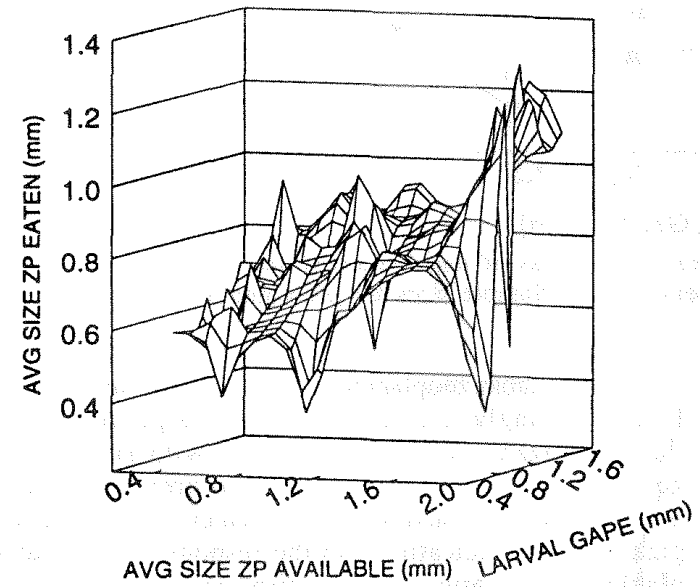

GIZZARD SHAD

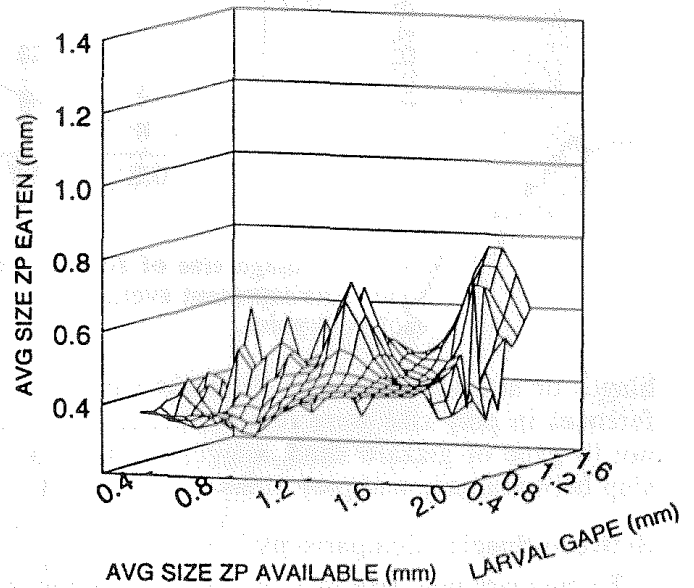

FIG. 4. Influence of increasing gape and average size of available zooplankton on average size of zooplankton eaten by larval bluegill $(n=135)$ and gizzard shad $(n=155)$. See Table 1 for regression statistics. 
TABLE 1. Regressions of average size of zooplankton eaten by larvae, calculated separately for bluegill $\left(n=135, r^{2}\right.$ $0.54)$ and gizzard shad $\left(n=155, r^{2}=0.12\right)$, as a function of average size of available zooplankton and of larval gape $(\mathrm{mm})$. The $F$ statistic and $p$ value are given for each full model, as well as the coefficients and associated standard error for individual model parameters. The $p$ value for model parameters corresponds to the contribution of each parameter to the model, i.e., $t$-test for coefficient $=0$.

\begin{tabular}{lcccccc}
\hline & \multicolumn{3}{c}{ Bluegill } & \multicolumn{3}{c}{ Gizzard shad } \\
\cline { 2 - 7 } \multicolumn{1}{c}{ Model: } \\
\cline { 2 - 8 } & $\begin{array}{c}F \text { statistic }=77.25 \\
\text { Coefficient }\end{array}$ & SE & $\begin{array}{c}p=0.0001 \\
p\end{array}$ & $\begin{array}{c}F \text { statistic }=10.83 \\
\text { Coefficient }\end{array}$ & SE & $\begin{array}{c}p=0.0001 \\
p\end{array}$ \\
\hline Intercept & 0.119 & 0.059 & 0.0414 & 0.344 & 0.047 & 0.0001 \\
Zooplankton size & 0.254 & 0.028 & 0.0001 & 0.132 & 0.028 & 0.0001 \\
Gape size & 0.351 & 0.051 & 0.0001 & $(-0.034)$ & 0.044 & 0.446 \\
\hline
\end{tabular}

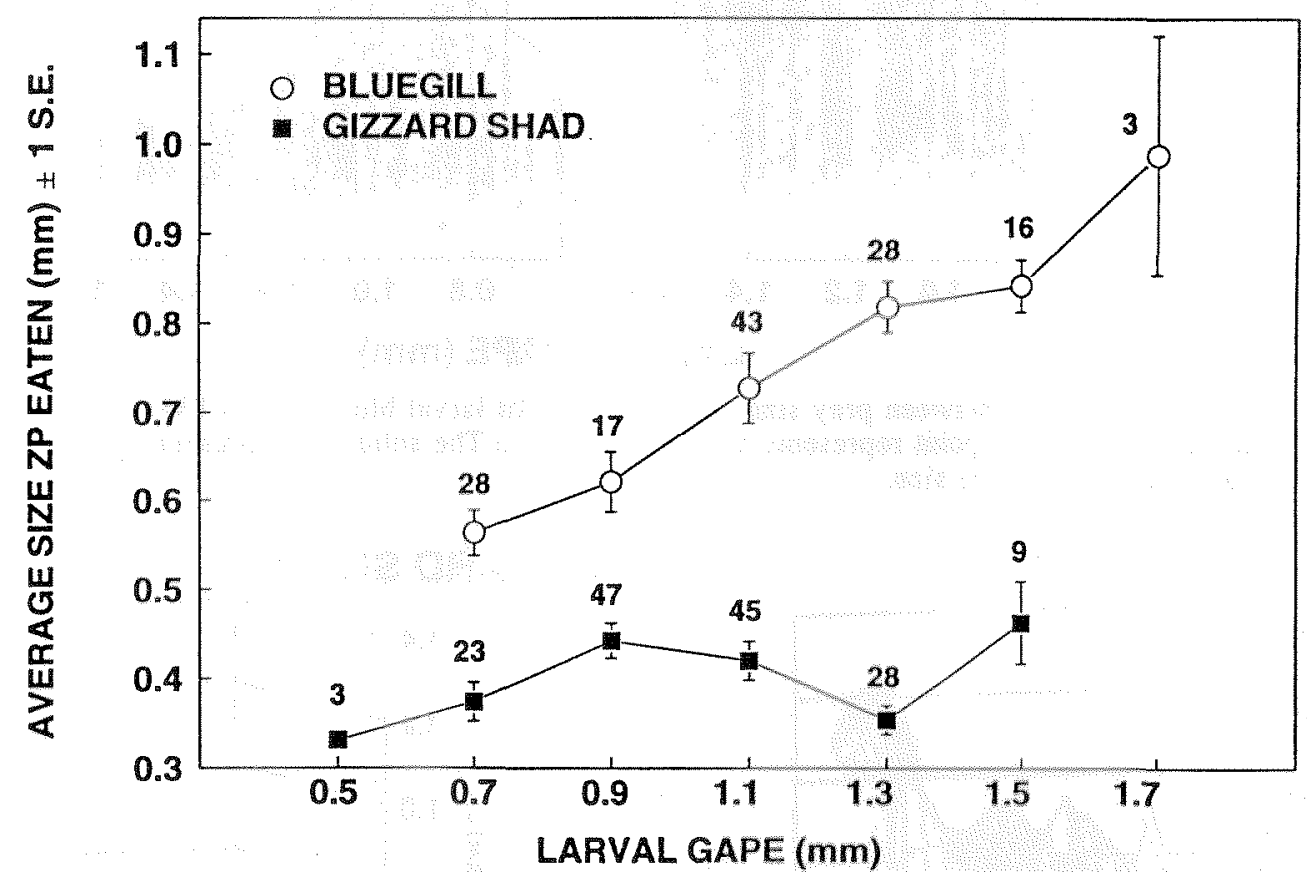

FIG. 5. Average size of zooplankton eaten by each size class of larval bluegill and gizzard shad. Data represent averages across all containers $\pm 1 \mathrm{SE}$. Sample sizes are presented above each data point.

\section{Between-Species Comparisons}

To compare prey size of larval bluegill and gizzard shad, we divided larvae into gape classes which spanned only $0.20 \mathrm{~mm}$ to minimize differences in gape among larvae within a size 
class, relative to the size range of zooplankton encountered. We calculated average size of zooplankton eaten by larvae in each gape class (across all containers), for each species, to determine if larvae with similar gapes ate similar-sized prey. Size of zooplankton eaten was influenced by both fish species (ANOVA: $\left.F_{1.12}=68.34, p=0.0001\right)$ and gape class $\left(F_{6.12}=6.88\right.$, $p=0.0001)$, as well as their interaction $\left(F_{5.12}=6.11, p=0.0001\right.$; Fig. 5). Bluegill consumed larger prey than gizzard shad of the same gape, a difference that increased with gape.

Our previous analysis of each species indicated that bluegill and gizzard shad differed in response to available zooplankton size. To evaluate this pattern further, we regressed average prey size of all larvae against fish species, average size of available zooplankton, and their interaction (Table 2). Not surprisingly, average prey size was greater for bluegill than for gizzard shad and increased with size of available zooplankton. Further, the increase in prey size as available zooplankton size increased was greater for bluegill than for gizzard shad, indicating that the response to available zooplankton size varied between fish species

To further characterize prey choice across zooplankton assemblages, we calculated sizeselectivity values for each gape class of larval bluegill and gizzard shad. Because size-selectivity values incorporate sizes of available zooplankton, we could confirm that differences between bluegill and gizzard shad prey size did not derive from differences in the size distribution of zooplankton assemblages available to the two species. This analysis also allowed us to explore whether increases in bluegill prey size were due solely to opportunistic feeding (prey size increases with available zooplankton size) or due to selective feeding on larger zoo plankton. In most cases, larvae consumed less than $25 \%$ of available zooplankton; only in 10 of 62 containers did larvae consume $\geq 25 \%$ of available zooplankton. Size-selectivity patterns were similar in analyses with and without these 10 containers, indicating that prey size selection was robust across zooplankton densities. Thus, we included all containers in our size-selectivity analysis.

To calculate selectivity, we partitioned gut and available zooplankton into seven size classes, representing 0.2-mm increments. We then calculated selectivity values for individual fish (for each zooplankton size class) and generated an average value for each larval size class. Bluegill consistently selected larger prey than similar-sized gizzard shad; further, bluegill selected larger zooplankton as gape increased whereas gizzard shad consistently selected the smallest zoo-plankton (Fig. 6).

TABLE 2. Regression of the average size of zooplankton eaten, including all larvae $\left(\mathrm{n}=290, r^{2}=0.60\right)$, as a function of fish species, average size of available zooplankton, and the interaction between these two variables. In this analysis, bluegill were designated as fish species $=1$ and gizzard shad as fish species $=2$ (therefore, the negative coefficients for fish species and fish species $\times$ available zooplankton size indicate that bluegill ate larger prey than gizzard shad and that these differences in prey size were more marked when large zooplankton were available). The $F$ statistic and $p$ value are given for the full model, as well as the coefficients and associated standard error for individual model parameters. The $p$ value for model parameters corresponds to the contribution of each parameter to the model, i.e., $t$-test for coefficient $=0$.

\begin{tabular}{|c|c|c|c|}
\hline $\begin{array}{c}\text { Model: } \\
\text { Parameter: }\end{array}$ & $\begin{array}{c}F \text { statistic }=144.91 \\
\text { Coefficient }\end{array}$ & $\mathrm{SE}$ & $\begin{array}{c}p=0.0001 \\
p\end{array}$ \\
\hline Intercept & 0.639 & 0.061 & 0.0001 \\
\hline Fish species & -0.163 & 0.039 & 0.0001 \\
\hline Zooplankton size & 0.447 & 0.065 & 0.0001 \\
\hline Fish species X zooplankton size & -0.160 & 0.043 & 0.0002 \\
\hline
\end{tabular}




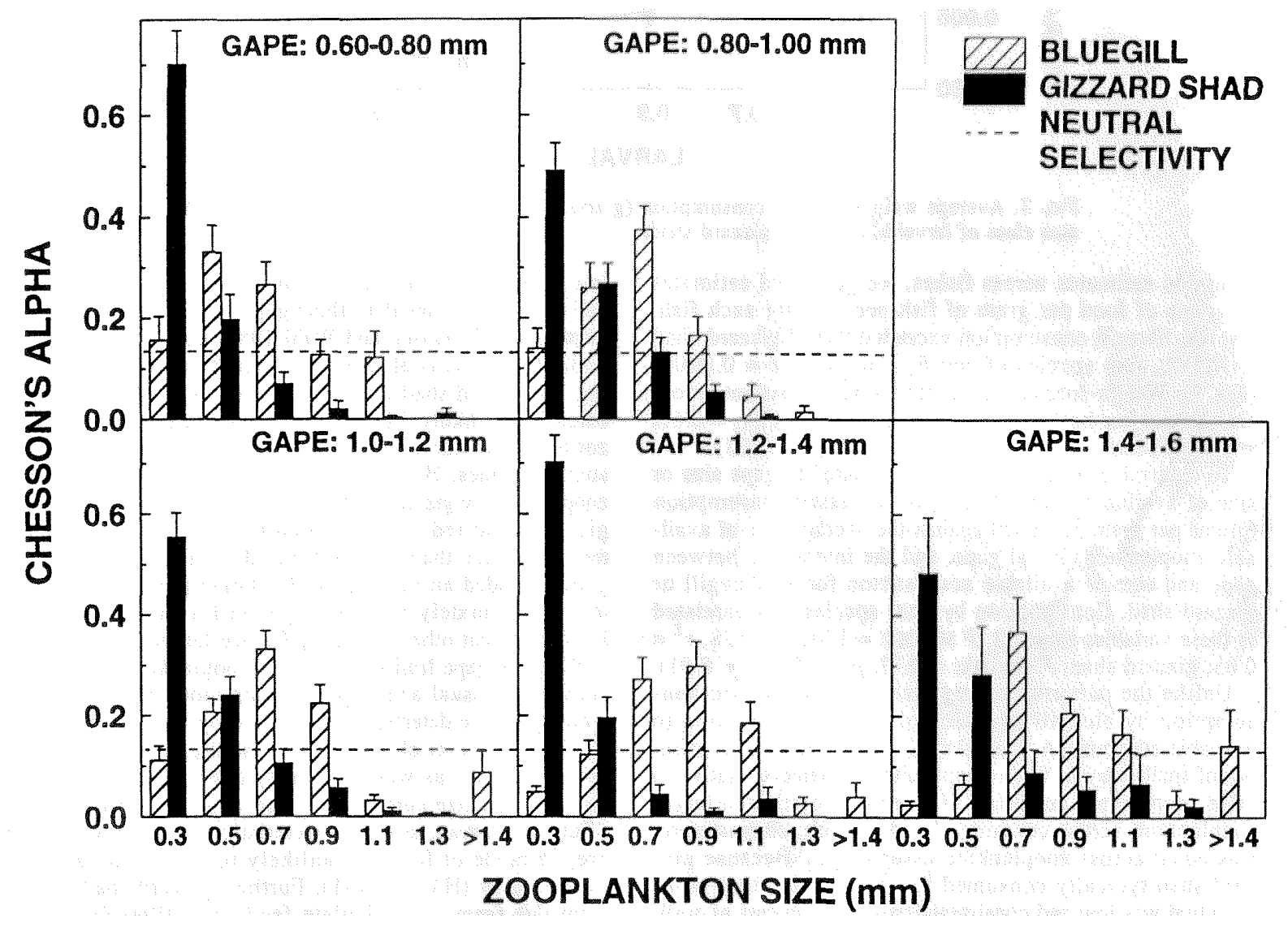

FIG. 6. Size selection (using Chesson's alpha, Chesson 1978, 1983) by larval bluegill and gizzard shad of each gape class. Data represent averages across all containers \pm 1 SE. The broken line represents neutral selection (i.e., 0.14, the reciprocal of the number of zooplankton size classes available).

\section{Weight-specific Consumption}

We also calculated the biomass of zooplankton consumed by larvae in each gape class to determine if consumption varied across zooplankton assemblages. To standardize consumption estimates across fishes, we generated estimates of grams of food per gram of fish per hour for each fish. Overall, bluegill consumption exceeded that of gizzard shad (ANOVA, fish species effect: $F_{1.12}=13.63, p=0.0003$ ) (Fig. 7). Weight-specific consumption was consistent across size classes for both species (size class effect: $\mathrm{F}_{6.12}=0.67, p=0.677$; interaction effect: $F_{5.12}=$ $1.21, p=0.305)$.

To determine if consumption was related to gape size or size of available zooplankton, we regressed consumption (grams per gram per hour) against the average size of available zooplankton, larval gape, and the interaction between gape and size of available zooplankton for all bluegill or gizzard shad. Consumption by both species was unrelated to these variables (bluegill: $F$ statistic $=1.31, p=0.28, r^{2}=0.03$; gizzard shad: $F$ statistic $=0.77, p=0.51, r^{2}=$ $0.01)$. 
Unlike the patterns in prey size, weight specific consumption by bluegill and gizzard shad was unrelated to available zooplankton size. Bluegill consumed a larger number of small prey in small zooplankton containers relative to large zooplankton containers. (Bluegill also selected larger zooplankton across containers). As a result, consumption was equal across zooplankton assemblages. Because gizzard shad typically consumed few small prey, their consumption was low and consistent across experiments as well.

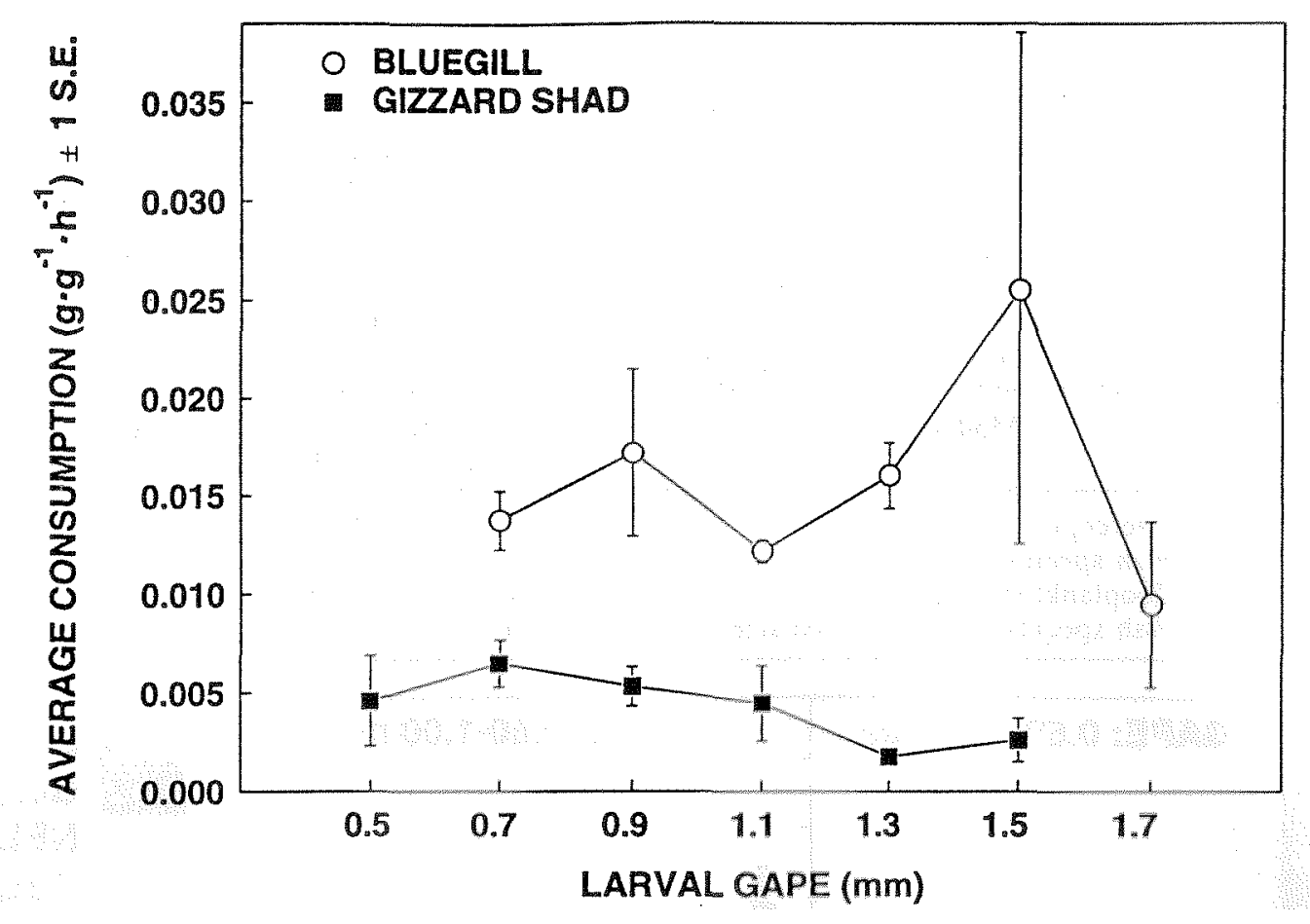

FIG. 7. Average weight-specific consumption (g zooplankton $\cdot \mathrm{g}^{-1} \cdot \mathrm{h}^{-1} \pm 1 \mathrm{SE}$ ) eaten by each size class of larval bluegill and gizzard shad.

Discussion

A Multispecies Approach to Recruitment: the Role of Larval Gape

Overall, gape provided insight into size selectivity. Bluegill, the large-gaped species, fed on larger prey than gizzard shad, the small-gaped species. However, gape - prey size relationships differed markedly between bluegill and gizzard shad. Larvae of these species with the same gape selected different prey sizes; selectivity patterns with increasing gape differed as well. Both bluegill and gizzard shad fed on prey smaller than their gape, as in previous studies (Arthur 1976; Hansen and Wahl 1981; Lemly and Dimmick 1982; Michaletz et al. 1987), but this trend was more striking for gizzard shad than for bluegill. Size of zooplankton eaten would likely fall below gape because our measure of zooplankton size did not include morphological features such as spines. However, the strong selectivity for small zooplankton by gizzard shad $(<0.50 \mathrm{~mm})$ clearly indicates that gizzard shad fed on zooplankton much smaller than the 
maximum size their gape would allow. Therefore, whereas gape provided an indication of relative prey size, it alone did not accurately predict prey size for these two fishes, indicating that other factors influence larval foraging.

Whereas gape limits the size of zooplankton that can be consumed, visual acuity or foraging mode may determine which prey are detected and captured by larval fish (Hunter 1981; Hairston et al. 1982). As visual particulate feeders, larval bluegill (as well as adults) likely select large prey (within gape size constraints). Larval gizzard shad, typical of clupeid larvae, use a characteristic S-posture to capture prey, a mode of foraging unlikely to obtain larger, more evasive prey (Hunter 1981). Further, gizzard shad switch from this form of particulate feeding to filter-feeding at about $25 \mathrm{~mm}$ (Cramer and Marzolf 1970; Guest et al. 1990). As filter-feeders, gizzard shad are not size selective predators; rather, they consume zooplankton with little ability to escape (Drenner et al. 1982). Gizzard shad $>25 \mathrm{~mm}$ in our experiments may have been filterfeeding, thus capturing smaller, more vulnerable prey items rather than the larger, more evasive ones. Thus, differences in foraging behavior between bluegill and gizzard shad may underlie their different gape - prey size relationships, illustrating that studies of morphological features, such as gape, must recognize that behavioral differences may modify the role of any morphological feature, complicating direct species comparisons.

Because rotifers and copepod nauplii were not included in our design, we likely overestimated gizzard shad prey size because these small prey often occur in diets of young-ofyear gizzard shad (Dettmers and Stein 1992; DeVries and Stein 1992). Hence, the disparity between bluegill and gizzard shad prey choice could be even greater. Further, gizzard shad and bluegill gapes differ most at smallest sizes; therefore, larvae smaller than those used may be even more vulnerable to the differential influence of zooplankton size and to food limitation in general. In particular, small gizzard shad larvae may require high densities of small zooplankton, such as rotifers and copepod nauplii, whereas bluegill may be able to consume larger zooplankton much earlier in their ontogeny.

\section{Zooplankton Size}

Implications for growth and survival

Given differences in prey choice between bluegill and gizzard shad, we hypothesized that differences in foraging success, resulting from differences in size of available zooplankton, would lead to differences in growth. To explore this issue, we calculated larval consumption during the foraging trials. While total weight-specific consumption did not vary in response to changes in available zooplankton size, as we would have predicted, this analysis is inconclusive because of the short-term nature of these experiments. Without estimates of foraging costs, such as search, capture, and assimilation, optimal zooplankton size for larval growth cannot be estimated. To quantify how zooplankton size influences larval fish growth, longer experiments in which growth is quantified are required. Growth differences resulting from zooplankton size could occur, even if prey biomass consumed is the same. Bluegill may spend more energy capturing the same overall biomass of prey when only small zooplankton are available as compared with when large zooplankton are available as well. Conversely, gizzard shad may invest more energy in search of a relatively low number of small zooplankton when the zooplankton assemblage is dominated by large individuals. Unfortunately, studies that have documented differences in young-of-year fish growth on different sizes of zooplankton have not 
measured larval consumption, making direct comparisons with our study difficult.

High zooplankton densities used in these experiments may have masked differences in consumption that could occur at low zooplankton densities. For example, when testing how zooplankton size influences growth of young-of-year yellow perch (Perca flavescens), Mills et al. (1989a) found that available zooplankton size was related to yellow perch growth when yellow perch were fed a $25 \%$ dry weight ration, but not when fed a $40 \%$ ration. Clearly, the energetics of foraging are likely to be influenced by both size and number of available zooplankton. High densities of zooplankton may alleviate, to some extent, the constraints that zooplankton size exerts on larval foraging.

Community implications

We contend that zooplankton size likely differentially affects growth and survival of larval fishes, particularly bluegill and gizzard shad. Specifically, systems containing large zooplankton may benefit young-of-year bluegill. Conversely, systems dominated by small zooplankton appear ideal for larval gizzard shad. Granted, systems dominated by large zooplankton will always contain some relatively small zooplankton in the form of early life stages of large zooplankton taxa. However, in systems dominated by large zooplankton taxa, both the relative and absolute abundance of these small zooplankton size classes will be lower than in a system (with similar total zooplankton densities) dominated by small zooplankton taxa. Therefore, encounter rates of larvae with these small zooplankton would be substantially lower (and thus foraging costs likely higher) in a system dominated by large zooplankton taxa.

Clearly, size structure of zooplankton assemblages varies considerably across systems (Brooks and Dodson 1965; Gannon and Stemberger 1978; Sprules 1980; Pace and Orcutt 1981; Bays and Crisman 1983; Pace 1986; Mills et al. 1987; Hall and Ehlinger 1989). In particular, many north temperate lakes are dominated by large zooplankton taxa (Brooks and Dodson 1965; Mills el al. 1987; Hall and Ehlinger 1989), in contrast with many Ohio reservoirs, in which small zooplankton taxa are most abundant (average size of zooplankton 0.3-0.5 mm; Bremigan et al. 1991; DeVries and Stein 1992). In turn, differences in the relative abundance of bluegill and gizzard shad between these two systems are evident as well. Ohio reservoirs typically support successful recruitment, and ultimately dense adult populations, of gizzard shad, which often vastly outnumber other fishes, such as bluegill (Johnson et al. 1986). While bluegill persist in Ohio reservoirs, they often do not reach densities typical of many north temperate lakes (i.e. in areas such as Wisconsin, Michigan, and New York). Gizzard shad, on the other hand, rarely reach high density in north temperate systems. However, the geographic distribution of gizzard shad extends north of the forty-fifth parallel (Becker 1983), indicating that temperature alone does not preclude them from all northern systems.

Throughout the foraging experiments, gizzard shad consistently selected and consumed small zooplankton, characteristic of many Ohio reservoirs. Conversely, bluegill consistently selected larger zooplankton that often are quite rare in Ohio reservoirs. Based on results of the foraging experiments, combined with field patterns in the distribution of these species, we hypothesize that differences in the size structure of zooplankton communities across systems could underlie patterns in species distributions. In particular, Ohio reservoirs, and other systems dominated by small zooplankton, may represent ideal foraging environments for gizzard shad. Gizzard shad typically spawn before bluegill and may reduce zooplankton abundances (Dettmers 
and Stein 1992; DeVries and Stein 1992). Therefore, bluegill may be disadvantaged in Ohio reservoirs due to both small zooplankton size and competition with gizzard shad for these less than ideal resources. Conversely, north temperate lakes dominated by larger zooplankton may represent ideal foraging environments for larval bluegill, but may constrain foraging success and ultimately recruitment of gizzard shad.

Acknowledgements:

We thank Shelley Arnott, Michael Arts, David Culver, Dennis DeVries, Edward Houde, Libby Marschall, Thomas Miller, Jeffrey Miner, James Rice, and Patricia Soranno for valuable reviews of earlier versions of this manuscript. Michael Arts generously provided the precision gape micrometer for our use. Financial support was provided by Electric Power Research Institute grant 91-07, Federal Aid in Fish Restoration Project F-57-R administered through the Ohio Division of Wildlife, Sigma Xi, and the Department of Zoology at The Ohio State University.

References:

ADAMS, S.M., R.B. MCLEAN, AND M.M. HUFFMAN. 1982. Structuring of a predator population through temperature-mediated effects on prey availability. Can. J. Fish. Aquat. Sci. 39: 1175-1184.

ARTHUR, D.K. 1976. Food and feeding of larvae of three fishes occurring in the California current, Sardinops sagax, Engraulis mordax, and Trachurus symmetricus. Fish. Bull. 74: 517-530.

ARTS, M.T., AND D.O. EVANS. 1987. Precision micrometer for measurement of mouth gape of larval fish. Can. J. Fish. Aquat. Sci. 44: 1782-1785.

BAYS, J.S., AND L. CRISMAN. 1983. Zooplankton and trophic state relationships in Florida lakes. Can. J. Fish. Aquat. Sci. 40: 1813-1819.

BECKER, G.C. 1983. Fishes of Wisconsin. University of Wisconsin Press, Madison, Wis.

BLAXTER, J.H.S. 1986. Development of sense organs and behaviour of teleost larvae with special reference to feeding and predator avoidance. Trans. Am. Fish. Soc. 115: 98-114.

Bremigan, M.T., E.M. LEWIS, M.B. Jones, R.A. SteIN, AND D.R. DeVRIES. 1991. Evaluating effects of stocking threadfin shad on young-of-year crappie, bluegill, and largemouth bass in Ohio lakes. Final Report, Federal Aid in Fish Restoration Project F-61-R, Study 15, Ohio Department of Natural Resources, Division of Wildlife, Columbus, Ohio.

BROOKS, J.L., AND S.I. DODSON. 1965. Predation, body size, and composition of plankton. Science (Wash., D.C.) 150: 28-35.

CANFIELD, T.J. 1988. Relations among zooplankton abundances, biomass, community structure, and lake trophic state in selected midwestern waterbodies. Master's thesis, University of Missouri, Columbia, Mo.

CHESSON, J. 1978. Measuring preference in selective predation. Ecology 59: 211-215.

CHESSON, J. 1983. The estimation and analysis of preference and its relationship to foraging models. Ecology 64: 1297-1304.

CRAMER, J.D., AND G.R. MARZOLF. 1970. Selective predation on zooplankton by gizzard shad. Trans. Am. Fish. Soc. 99: 320-332.

CROWDeR, J.B., M.E. MCDONALD, AND J.A. RICE. 1987. Understanding recruitment of Lake Michigan fishes: the importance of size-based interactions between fish and zooplankton. Can. J. Fish. Aquat. Sci. 44(Suppl. 2): 141-147.

DETTMERS, J.M., AND R.A. STEIN. 1992. Food consumption by larval gizzard shad: zooplankton effects and its implications for reservoir communities. Trans. Am. Fish. Soc. 121: 494-507.

DeVRIES, D.R., AND R.A. STEIN. 1992. Complex interactions among fish and zooplankton as influenced by an open-water planktivore. Can. J. Fish. Aquat. Sci. 49: 1216-1227.

DRENNER, R.W., W.J. O'BRIEN, AND J.R. MUMMERT. 1982. Filter-feeding rates of gizzard shad. Trans. Am. Fish. Soc. 111: 210-215.

FORNEY, J.L. 1976. Year-class formation in the walleye (Stizostedion vitreum vitreum) population of Oneida Lake, New York, 1966-1973. J. Fish. Res. Board Can. 33: 783-792. 
FRANK, K.T., AND W.C. LEGGETT. 1986. Effect of prey abundance and size on the growth and survival of larval fish: an experimental study employing large volume enclosures. Mar. Ecol. Prog. Ser. 34: 11-22.

GANNON, J.E., AND R.S. STEMBERGER. 1978. Zooplankton (especially crustaceans and rotifers) as indicators of water quality. Trans. Am. Microsc. Soc. 97: 16-35.

Guest, W.C., R.W. Drenner, S.T. ThrelKeld, F.D. Martin, AND J.D. SMith. 1990. Effects of gizzard shad and threadfin shad on zooplankton and young-of-the-year white crappie production. Trans. Am. Fish. Soc. 119: 529-536.

HAIRSTON, N.G. JR., K.T. LI, AND S.S. EASTER, JR. 1982. Fish vision and the detection fo planktonic prey. Science (Wash., D.C.) 218: 1240-1242.

HALL, D.J., AND T.J. EHLINGER. 1989. Perturbation, planktivory, and pelagic community structure: the consequence of winterkill in a small lake. Can. J. Fish. Aquat. Sci. 46: 2203-2209.

HANSEN, M.J., AND D.H. WAHL. 1981. Selection of small Daphnia pulex by yellow perch fry in Oneida Lake, New York. Trans. Am. Fish. Soc. 110: 64-71.

HARTMANN, J. 1986. Interspecific predictors of selected prey of young fishes. Arch. Hydrobiol. 22: $373-386$.

HUNTER. J.R. 1981. Feeding ecology and predation of marine fish larvae, p. 34-77. In R. Lasker [ed.] Marine fish larvae. Morphology, ecology, and relation to fisheries. University of Washington Press. Seattle, Wash.

JOHNSON, B.M., R.A. STEIN. AND R.F. CARLINE. 1986. Use of a quadrat rotenone technique and bioenergetics modelling to evaluate prey availability to stocked piscivores. Trans. Am. Fish. Soc. 117: 127141.

LEMLY, A.D., AND J.F. DIMMICK. 1982. Growth of young-of-the-year and yearling centrachids in relation to zooplankton in the littoral zone of lakes. Copeia 1982: 305-321.

Luecke, C., J.A. Rice, L.B. Crowder, S.E. YeO, AND F.P. BinKowSKi. 1990. Recruitment mechanisms of bloater in Lake Michigan: an analysis of the predatory gaunlet Can. J. Fish. Aquat. Sci. 47: 524-532.

Michaletz, P.H., D.G. UnKenholz, AND C.C. StonE. 1987. Prey size selectivity and food partitioning of zooplanktivorous age-0 fishes in Lake Francis Case, South Dakota Am. Midl. Nat. 117: 126-138.

MiLler, T.J., L.B. CROWDER. AND F.P. BINKOWSKI. 1990. Effects of changes in the zooplankton assemblage on growth of bloater and implications for recruitment success. Trans. Am. Fish. Soc. 119: 483-491.

Miller, T.J., L.B. Crowder, J.A. Rice, ANd E.A. MARSChall. 1988. Larval size and recruitment mechanisms in fishes: toward a conceptual framework. Can. J. Fish. Aquat. Sci.45: 1657-1670.

MiLLS, E.L., D.M. GREEN, AND A. SCHIAVONE,. JR. 1987. Use of zooplankton size to assess the community structure of fish populations in fresh-water lakes. N. Am. J. Fish. Manage. 7: 369-378.

Mills, E.L., M.V. Pol, R.E. Sherman, AND T.B. CulVER. 1989a. Interrelationships between prey body size and growth of age-0 yellow perch. Trans. Am. Fish. Soc. 118: 1-10.

MiLls, E.L., R. SHERMAN, AND D.S. ROBSON. 1989B. Effect of zooplankton and body size on growth of age-0 yellow perch (Perca flavescens) in Oneida Lake, New York, 1975-86 Can. J. Fish. Aquat. Sci. 46: 880- 886.

NoBLE, R.L. 1975. Growth of young yellow perch (Perca flavescens) in relation to zooplankton populations. Trans. Am. Fish. Soc. 4: 731743.

PACE, M.L. 1986. An empirical analysis of zooplankton community size structure across lake trophic gradients. Limnol. Oceanogr. 31: 45-55.

PACE, M.L., AND J.D. ORCUTT, JR. 1981. The relative importance of protozoans, rotifers, and crustaceans in a freshwater zooplankton community. Limnol. Oceanogr. 26: 822-830.

PEPIN, P. 1991. Effect of temperature and size on development, mortality, and survival rates of the pelagic early life history stages of marine fish. Can. J. Fish. Aquat. Sci. 48: 503-518

Post, J.R., AND A.B. PRANKEVICIUS. 1987. Size-selective mortality in young-of-year yellow perch (Perca flavescens): evidence from otolith microstructure. Can. J. Fish. Aquat. Sci. 44: 1840-1847.

RiCE, J.A., L.B. CROWDER, AND M.E. HOLEY. 1987. Exploration of mechanisms regulating larval survival in Lake Michigan bloater recruitment analysis based on characteristics of individual larvae. Trans. Am. Fish. Soc. 116: 703-718.

SCHAEL, D.M., L.G. RUDSTAM, AND J.R. POST. 1991. Gape limitation and prey selection in 
larval yellow perch (Perca flavescens), freshwater drum \{Aplodinotus grunniens), and black crappie (Pomoxis nigromaculatis). Can. J. Fish. Aquat. Sci. 38: 1919-1925.

SPRULES, W.G. 1980. Zoogeographic patterns in the size structure of zooplankton communities, with possible applications to lake ecosystem modeling and management. Am. Soc. Limnol. Oceanogr. Spec. Symp. 3: 642-656.

WARE, D.M. 1975. Relation between egg size, growth, and natural mortality of larval fish. J. Fish. Res. Board Can. 32: 2503-2512.

WARE, D.M. 1977. Spawning time and egg size of Atlantic mackerel, Scomber scombrus, in relation to the plankton. J. Fish. Res. Board Can. 34: 2308-2315.

WONG, H., AND F.J. WARD. 1972. Size selection of Daphnia pulicaria by yellow perch (Perca flavescens) fry in West Blue Lake, Manitoba. J. Fish. Res. Board Can. 29: 1761-1764. 